\title{
The measurement of production rates of volatile fatty acids in the caecum of the conscious rabbit
}

\author{
BY D. S. PARKER \\ Department of Physiology and Biochemistry, University of Reading, \\ Whiteknights, Reading RG6 $2 A \mathcal{F}$ \\ (Received 18 September I975 - Accepted I $_{5}$ December 1975)
}

\begin{abstract}
r. The decrease in specific radioactivity of individual volatile fatty acids (VFA) after a single injection of tracer was monitored. The results obtained indicated the occurrence of a first-order process.

2. Regression analysis indicated the high flux of VFA through the caecal pool, equivalent to $30 \%$ of the maintenance energy requirement of the animal.

3. Interconversion of VFA was monitored, and results indicated substantial synthesis of butyric acid from acetic acid.

4. Results were obtained from animals on two dietary regimens, and these were compared with results reported for other species.
\end{abstract}

The production of volatile fatty acids (VFA) in the caecum of the rabbit has been known for some time (Elsden, Hitchcock, Marshall \& Phillipson, 1946) and the process has been associated with the digestion of cellulose by the animal, analogous to digestion in the rumen. In vitro studies have been made to assess the production of VFA by rabbit caecal material (Hoover \& Heitmann, 1972), but the problem of obtaining suitable samples has prevented similar studies in the intact animal. Using the method of dialysis of caecal material outlined in a previous paper (Parker \& McMillan, 1976) it was decided to undertake tracer studies on VFA metabolism in the caecum.

The methods available for studies of this type in the rumen have been reviewed extensively (Leng, 1970; Annison, 1972). Although the technique of continuous infusion of tracer is generally accepted as giving a more precise assessment of VFA production rates and interconversion, a good over-all assessment of the turnover of the VFA can be obtained from a single injection of tracer, and this was the method adopted here. This method involves monitoring the decrease in specific radioactivity (SR) of the injected VFA at known time intervals after injection, and the kinetic characteristics of the VFA are calculated from these measurements (Gray, Jones \& Pilgrim, I960; Knox, Black \& Kleiber, I967). Rumen studies using isotope dilution techniques have underlined the need for effective mixing of the tracer with the VFA pool, and experiments with sheep (Faichney, 1969) have indicated that mixing of the viscous contents may be a problem in samples taken from the caecum. The results of preliminary studies with a dialysis probe inserted into the caecum of the rabbit indicated that the tracer is rapidly dispersed in the caecal material, and it is possible to begin sampling $30 \mathrm{~min}$ after injection. The rapid mixing of caecal contents described by Pickard \& Stevens (1972) appears to continue after the 
implantation of the dialysis probe and ensures that samples obtained by this method are representative of the digesta present. In the experiments described in this paper individual ${ }^{14} \mathrm{C}$-labelled VFA were injected into the caecum of the conscious rabbit and the loss of the radioactivity from the VFA pool determined.

\section{EXPERIMENTAL}

\section{Animals}

Mature, male New Zealand White rabbits weighing $2 \cdot 5-3 \mathrm{~kg}$ were used throughout the experiments. The animals were fed on a diet of laboratory pellets (E. Dixon \& Sons Ltd, Ware) and water was available at all times.

\section{Collection of VFA and infusion of tracer}

The collection of samples of caecal VFA was made using the method described previously (Parker \& McMillan, 1976). The caecal probe was modified to include a third catheter for the injection of the tracer. This catheter was attached to the inlet and outlet catheters of the probe so that the end of the catheter was $70 \mathrm{~mm}$ from the top of the probe. In this way it was hoped that the radioactive material infused would be thoroughly mixed with the caecal contents before dialysis and collection of samples.

Infusion consisted of a single injection of individual radioactively labelled VFA (Radiochemical Centre, Amersham, Bucks.), sodium $\left[\mathrm{I}^{-14} \mathrm{C}\right]$ acetate ( $5 \mu \mathrm{Ci}$ ), sodium $\left[\mathrm{I}^{14} \mathrm{C}\right]$ butyrate $(20 \mu \mathrm{Ci})$ or sodium $\left[\mathrm{I}-{ }^{14} \mathrm{C}\right]$ propionate $(20 \mu \mathrm{Ci})$ in saline $(\mathrm{I} \mathrm{ml}$, $9 \mathrm{~g} \mathrm{NaCl} / \mathrm{l}$ ), washed in with a further I $\mathrm{ml}$ saline. Samples of dialysate were collected for periods of $15 \mathrm{~min}$ after the injection and stored at $-20^{\circ}$ until analysed.

\section{Analysis of VFA}

The SR of the individual VFA present in the samples was determined using a gas-liquid chromatograph (GLC) (Model ro4; Pye Unicam Ltd, Cambridge) linked to a radio-gas chromatography system (Panax Instruments Ltd, Surrey). In this system the effluent from the column is split before it enters the flame ionization detector (FID) of the GLC and a proportion is diverted to the radio-gas detector. The $\mathrm{C}$ in this portion of the sample is oxidized at $65^{\circ}$ in a furnace-tube packed with copper oxide and the ${ }^{14} \mathrm{CO}_{2}$ produced is measured using a gas-flow proportional counter. In order to determine the amount of the individual VFA present in the dialysate an internal standard $\left(5^{\circ} .03 \mu \mathrm{mol}\right.$ isovaleric acid) was added to the sample before analysis. The $\mathrm{pH}$ of the samples were then adjusted to 9.0 with 0.1 M-sodium hydroxide and evaporated to dryness under infrared lamps. Immediately before analysis the VFA were taken up in $100 \mu 1 \mathrm{I} \cdot 5 \mathrm{M}$-sulphuric acid-triple-distilled formic acid $(3: 2, \mathrm{v} / \mathrm{v})$ and a ro $\mu \mathrm{l}$ sample was injected onto the column. The GLC column was packed with Chromosorb IOI (Phase Separations Ltd, Queensferry, Clwyd, $\mathrm{N}$. Wales) and run isothermally at $\mathrm{I} 95^{\circ}$ using argon $-\mathrm{CO}_{2}(95: 5, \mathrm{v} / \mathrm{v})$ as the carrier gas. The $\mathrm{CO}_{2}$ in the carrier gas acts as a proportional counting gas in the gas-flow counter, therefore $\mathrm{CO}_{2}$ does not have to be added to the gas stream before it enters 


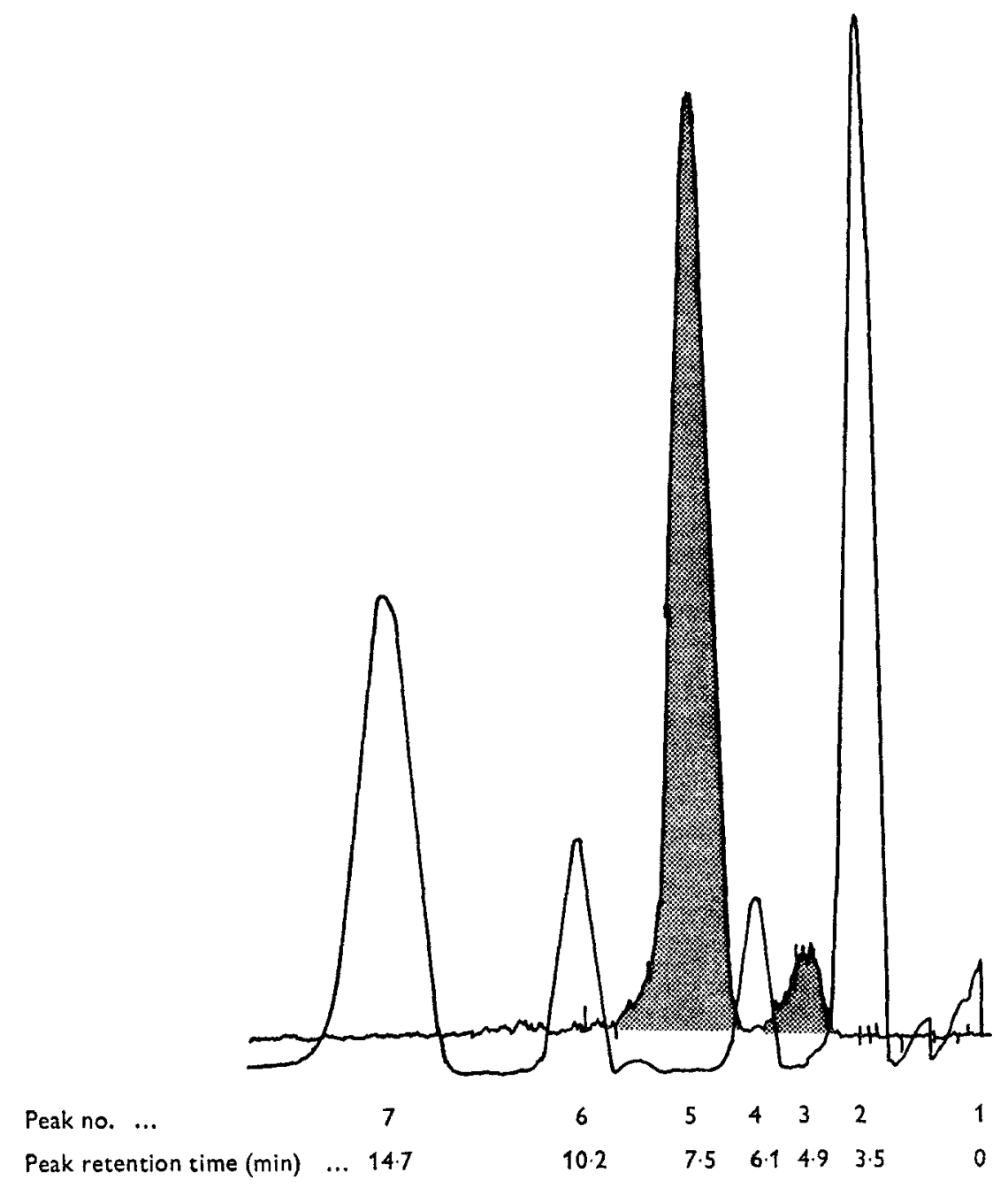

Fig. I. A representative recorder trace obtained from the radio-gas chromatograph showing the amount ( $\square$, 'mass' peaks) of individual volatile fatty acids (VFA), and the amount of radioactivity (圈, 'radioactivity' peaks) associated with each VFA, in caecal samples from rabbits after a single injection of individual ${ }^{14} \mathrm{C}$-labelled VFA. (I) Injection of caecal sample onto column of gas-liquid chromatograph; (2) 'mass' peak for acetic acid; (3) 'radioactivity' peak for acetic acid; (4) 'mass' peak for propionic acid; (5) 'radioactivity' peak for propionic acid; (6) 'mass' peak for butyric acid; (7) 'mass' peak for isovaleric acid (internal standard). For details of procedures, see p. 62 .

the counter. The outputs from the FID and the radio-gas counter were connected to a twin-pen recorder (Servoscribe 2; Smiths Industries Ltd, London NW2) and a recorder trace similar to that shown in Fig. I was obtained. The area of the 'mass' peak for individual VFA was determined by triangulation, converted for detector response and compared with that of the internal standard. The amount of radioactivity was determined using the number of counts recorded for the duration of the peak on an integrated printer, this value was corrected for the split ratio and 


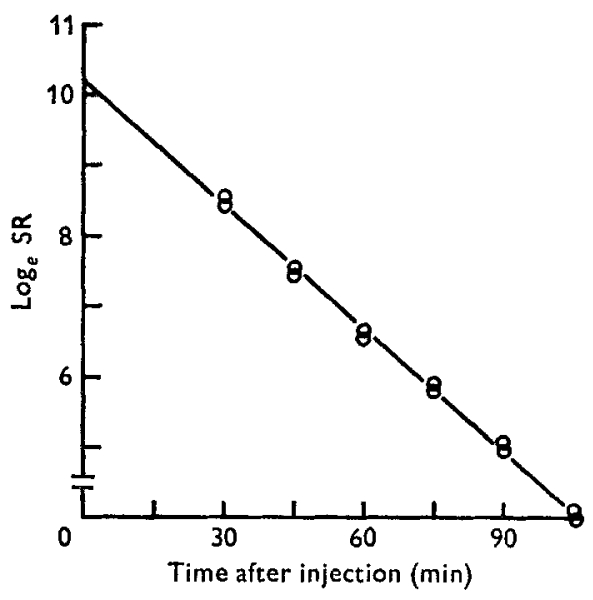

Fig. 2

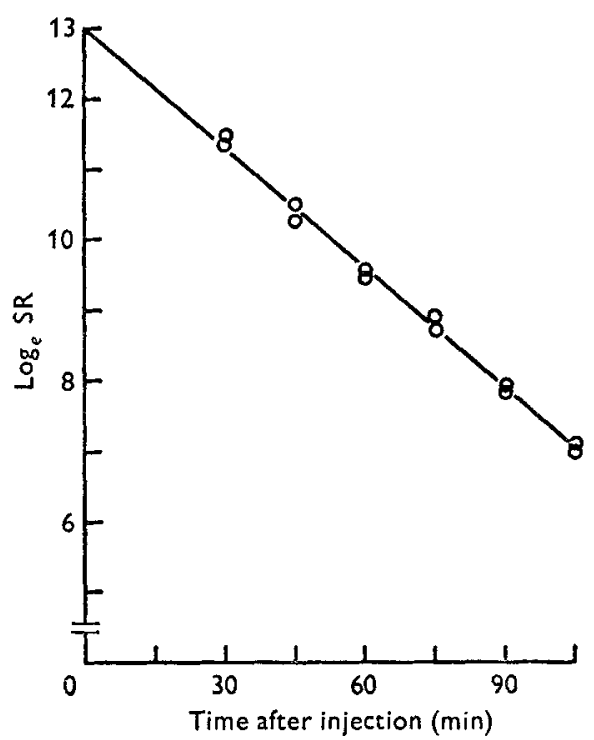

Fig. 3

Fig. 2. Decrease in specific radioactivity (SR) (disintegrations $/ \mathrm{min}$ per $\mu \mathrm{mol}$ ) of acetic acid in the caecum of one rabbit with time after injection $(\mathrm{min})$ of $15 \mu \mathrm{Ci}$ sodium $\left[{ }^{1-14} \mathrm{C}\right]$ acetate.

Fig. 3. Decrease in specific radioactivity (SR) (disintegrations/min per $\mu \mathrm{mol}$ ) of propionic acid in the caecum of one rabbit with time after injection (min) of $20 \mu \mathrm{Ci}$ sodium $\left[\mathrm{I}-{ }^{14} \mathrm{C}\right]-$ propionate.

efficiency of counting under operational conditions as determined using a standard labelled-VFA solution. Therefore, the SR of individual VFA in the samples could be determined in a single run on the GLC.

\section{RESULTS}

A series of single injections of individual labelled VFA were undertaken and the dialysate from the caecal probe analysed. It had been hoped to measure production rates of all three VFA in each rabbit used but this was not always possible due to variation in the effective life of the probe membrane. The results given, therefore, are those obtained from experiments with six rabbits on each of two feeding regimens, ad lib. feeding or $100 \mathrm{~g}$ food/d.

It was found that the SR of the individual VFA did not reach a maximum in the dialysate until $30 \mathrm{~min}$ after injection of the tracer; this represented the time required for complete mixing of the tracer and the caecal contents. In most instances a semi$\log$ plot of decrease in SR $v$. time after injection resulted in a straight line, as shown in Figs. 2-4 for the three VFA injected separately into one of the rabbits. This pattern indicated the occurrence of a first-order process and the characteristics of the VFA in the caecal pool were calculated on this basis. The regression line calculated by the method of least squares using the values obtained from each injection was used to calculate: ( $\mathrm{I}$ ) turnover rate (exponential regression of SR of VFA $v$. time after injection: $100 \times k(\% / \mathrm{min})$, where $k$ is the rate-constant from the regression 


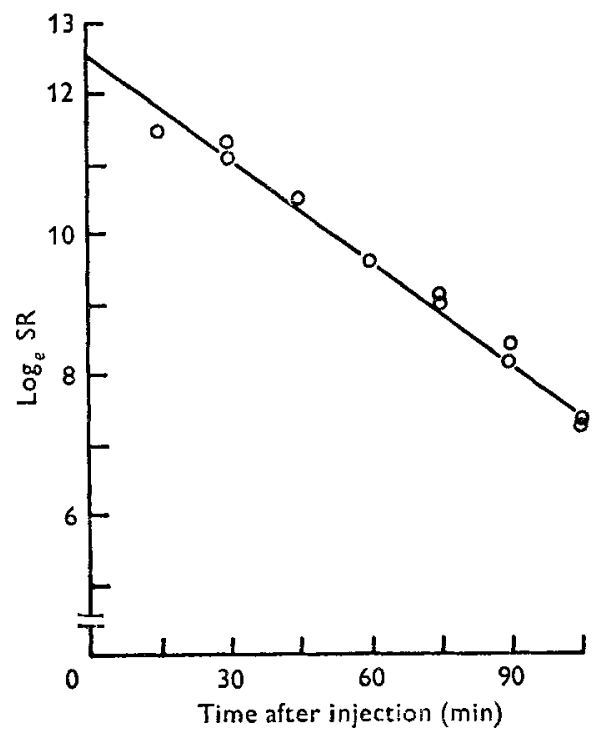

Fig. 4. Decrease in specific radioactivity (SR) (disintegrations $/ \mathrm{min}$ per $\mu \mathrm{mol}$ ) of butyric acid in the caecum of one rabbit with time after injection (min) of $20 \mu \mathrm{Ci}$ sodium $\left[1-{ }^{14} \mathrm{C}\right]$ butyrate.

Table I. Kinetic characteristics of volatile fatty acids $(V F A)$ in the caecum of rabbits given $100 \mathrm{~g}$ food/d, calculated from values obtained from the regression line of specific radioactivity of VFA v. time after a single injection of individual ${ }^{14} C$-labelled $V F A^{*}$

(Mean values for six rabbits)

\begin{tabular}{cccc} 
VFA & $\begin{array}{c}\text { Pool size } \\
(\mathrm{mmol})\end{array}$ & $\begin{array}{c}\text { Turnover rate } \\
(\% / \mathrm{min})\end{array}$ & $\begin{array}{c}\text { Exchange rate } \\
(\mu \mathrm{mol} / \mathrm{min})\end{array}$ \\
Acetic acid & 6.712 & 3.93 & 283.9 \\
& 4.008 & 4.54 & 180.4 \\
& 3.177 & 3.25 & 103.5 \\
Propionic acid & 1.214 & 5.82 & 70.74 \\
& 0.118 & 5.57 & 6.62 \\
0.098 & 5.66 & 5.60 \\
Butyric acid & 0.297 & 5.64 & 16.70 \\
& 0.086 & 3.53 & 3.04 \\
& 0.312 & 7.23 & 22.66 \\
& 0.329 & 8.48 & 27.91 \\
\multirow{2}{*}{ * For details of experimental procedures, see p. 62.}
\end{tabular}

equation); (2) pool size (injected dose $\div \mathrm{SR}$ at o min, intercept of regression line for SR of VFA v. time after injection); (3) exchange rate or total flux through VFA pool including interconversion (pool size $\times k$ ) (Knox et al. 1967).

The results of these calculations for individual VFA injections are given in Tables $\mathbf{I}$ and 2 for rabbits on the two feeding regimens. In the animals given $100 \mathrm{~g}$ food $/ \mathrm{d}$, each labelled VFA was injected $7 \mathrm{~h}$ after feeding, when it was considered that maximal VFA production had been reached (Parker \& McMillan, I976). The high 
Table 2. Kinetic characteristics of volatile fatty acids (VFA) in the caecum of rabbits fed ad lib., calculated from values obtained from the regression line of specific radioactivity of VFA v, time after a single injection of individual ${ }^{14} \mathrm{C}$-labelled $V F A^{*}$

(Mean values for six rabbits)

$\begin{array}{cccc}\text { VFA } & \begin{array}{c}\text { Pool size } \\ (\mathrm{mmol})\end{array} & \begin{array}{c}\text { Turnover rate } \\ (\% / \mathrm{min})\end{array} & \begin{array}{c}\text { Exchange rate } \\ (\mu \mathrm{mol} / \mathrm{min})\end{array} \\ \text { Acetic acid } & 5.409 & \mathbf{1 . 6 3} & 88.20 \\ & 2.699 & 1.78 & 48.07 \\ & 3.784 & 2.33 & 88.34 \\ \text { Propionic acid } & 3.211 & 3.67 & 117.8 \\ & 0.193 & 3.84 & 7.41 \\ & 0.264 & 3.50 & 9.26 \\ \text { Butyric acid } & 0.312 & 2.91 & 9.10 \\ & 0.164 & 5.60 & 9.20 \\ & 0.481 & 5.90 & 28.39 \\ & 0.766 & 2.99 & 22.90 \\ & 0.969 & 2.97 & 28.89 \\ & 0.108 & 5.14 & 5.55\end{array}$

* For details of experimental procedures, see p. 62.

Table 3. Kinetic characteristics of volatile fatty acids (VFA) in the caecum of rabbits given $100 \mathrm{~g}$ food/d or fed ad lib., calculated from values obtained from the regression line of specific radioactivity of VFA v. time after a single injection of individual ${ }^{14}$ C-labelled VFA*

(Mean values with their standard errors for four determinations)

\begin{tabular}{|c|c|c|c|c|c|c|c|c|}
\hline \multirow[b]{2}{*}{ VFA } & \multirow[b]{2}{*}{$\begin{array}{l}\text { Feeding } \\
\text { regimen }\end{array}$} & \multicolumn{2}{|c|}{$\begin{array}{c}\text { Pool size } \\
\text { (mmol) }\end{array}$} & \multicolumn{2}{|c|}{$\begin{array}{c}\text { Turnover rate } \\
(\% / \mathrm{min})\end{array}$} & \multicolumn{2}{|c|}{$\begin{array}{c}\text { Exchange rate } \\
(\mu \mathrm{mol} / \mathrm{min})\end{array}$} & \multirow{2}{*}{$\begin{array}{c}\text { Total } \\
\text { flux through } \\
\text { pool } \\
\text { (mmol/d) }\end{array}$} \\
\hline & & Mean & $\mathrm{SE}$ & Mean & SE & Mean & SE & \\
\hline Acetic acid & $\begin{array}{l}\mathrm{I} 00 \mathrm{~g} / \mathrm{d} \\
\text { ad lib. }\end{array}$ & $\begin{array}{l}3.777 \\
3.768\end{array}$ & $\begin{array}{l}I \cdot 140 \\
0.592\end{array}$ & $\begin{array}{l}4 \cdot 385 \\
2 \cdot 352\end{array}$ & $\begin{array}{l}0.546 \\
0.464\end{array}$ & $\begin{array}{l}159 \cdot 6 \\
85.59\end{array}$ & $\begin{array}{l}47 \cdot 36 \\
1430\end{array}$ & $\begin{array}{l}229 \cdot 8 \\
123 \cdot 2\end{array}$ \\
\hline Propionic acid & $\begin{array}{l}100 \mathrm{~g} / \mathrm{d} \\
\text { ad lib. }\end{array}$ & $\begin{array}{l}0.149 \\
0.233\end{array}$ & $\begin{array}{l}0.049 \\
0.033\end{array}$ & $\begin{array}{l}5.097 \\
3.962\end{array}$ & $\begin{array}{l}0.526 \\
0.578\end{array}$ & $\begin{array}{l}6 \cdot 489 \\
8 \cdot 742\end{array}$ & $\begin{array}{l}3.55 \\
0.445\end{array}$ & $\begin{array}{l}9 \cdot 344 \\
12 \cdot 58\end{array}$ \\
\hline Butyric acid & $\begin{array}{l}\mathrm{r} \circ \mathrm{g} / \mathrm{d} \\
\text { ad lib. }\end{array}$ & $\begin{array}{l}0.243 \\
0.581\end{array}$ & $\begin{array}{l}0.046 \\
0.186\end{array}$ & $\begin{array}{l}5.075 \\
4.250\end{array}$ & $\begin{array}{l}x \cdot 778 \\
0.749\end{array}$ & $\begin{array}{l}17 \cdot 36 \\
21 \cdot 43\end{array}$ & $\begin{array}{l}4 \cdot 745 \\
5 \cdot 373\end{array}$ & $\begin{array}{l}24.99 \\
30 \cdot 86\end{array}$ \\
\hline
\end{tabular}

Analysis of variance of results to determine whether the kinetic characteristics of the VFA differed significantly between the two feeding regimens indicated: for pool size of VFA, no significant difference; for turnover rate of VFA, values were significantly different $(P<0.01)$.

* For details of experimental procedures, see p. 62 .

turnover rates obtained are emphasized by the calculation of the total flux of VFA. through the caecum of the rabbit in $24 \mathrm{~h}$ (Table 3). Table 3 includes the results of analysis of variance tests to determine the level of significance of any difference between the VFA pool sizes and turnover rates on the two feeding regimens. Feeding $100 \mathrm{~g}$ food/d resulted in higher turnover rates for all VFA at the time of maximal VFA production, although acetic acid was the only VFA which had a marked variation in total flux in $24 \mathrm{~h}$, reflecting the much lower turnover rate when the rabbit was fed ad lib. 


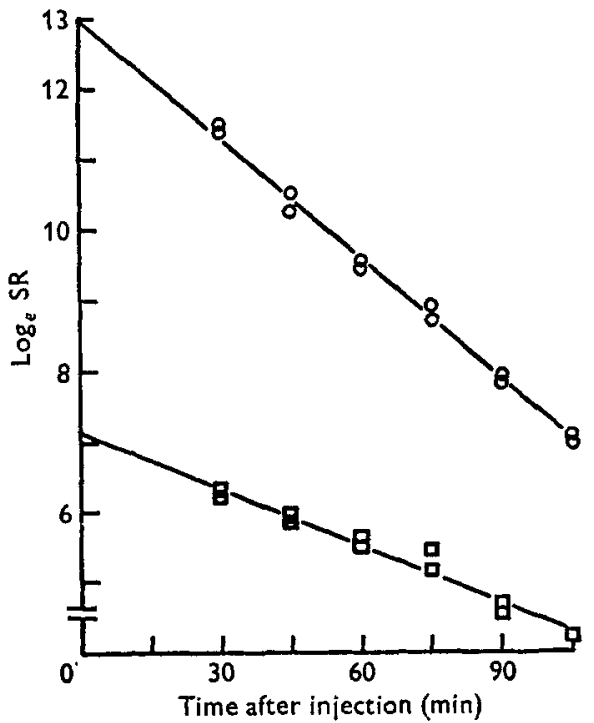

Fig. 5. Interconversion of volatile fatty acids in the caecum of the rabbit. Decrease in specific radioactivity (SR) (disintegrations/min per $\mu \mathrm{mol}$ ) of the precursor propionic acid and the product acetic acid with time after injection $(\mathrm{min})$ of $20 \mu \mathrm{Ci}$ sodium $\left[\mathrm{I}-{ }^{14} \mathrm{C}\right]$ propionate. $(\mathrm{O}-\mathrm{O})$, Injected propionic acid; $(\square-\square)$, product acetic acid.

Table 4. Interconversion of volatile fatty acids (VFA) in the caecal contents of rabbits given roo $g$ foodld or fed ad lib., calculated from the specific radioactivity $(S R)$ ratio* (Knox, Black $\Xi^{\circ}$ Kleiber, 1967) and values obtained from the decrease in $S R$ of VFA with time after a single injection of individual ${ }^{14} \mathrm{C}$-labelled $\mathrm{VFA} \uparrow$

(Mean values for six rabbits/dietary treatment)

$\begin{array}{cccc}\text { Precursor } & \text { Feeding regimen } & \text { Acetic acid } & \text { Butyric acid } \\ \text { Acetic acid } & 100 \mathrm{~g} / \mathrm{d} & - & 0.81 \mathrm{r} \\ & \text { ad lib. } & - & 0.587 \\ \text { Propionic acid } & 100 \mathrm{~g} / \mathrm{d} & 0.0036 & - \\ & a d \mathrm{lib} . & 0.0073 & - \\ \text { Butyric acid } & 100 \mathrm{~g} / \mathrm{d} & 0.055 & - \\ & a d \mathrm{lib} . & 0.059 & -\end{array}$

* $\int_{0}^{\varepsilon} \lambda \mathrm{d} t:{ }_{\mathrm{v}} \int^{\epsilon} \pi \mathrm{d} t$, where $\lambda$ is the SR of the product $(\mu \mathrm{Ci} / \mathrm{g}$ atom $\mathrm{C}), \pi$ is the SR of the precursor $(\mu \mathrm{Ci} / \mathrm{g}$ atom $C$ ) and $t$ is time after injection.

+ For details of experimental procedures, see p. 62.

The interconversion of VFA within the total pool can also be assessed from these experiments by comparison of the SR kinetics of the precursor VFA and its product (Fig. 5). This may be represented by the calculation of the SR ratio, ${ }_{0}^{\epsilon} \lambda \mathrm{d} t: \int_{0}^{e} \pi \mathrm{d} t$, where $\lambda$ is the SR of the product ( $\mu \mathrm{Ci} / \mathrm{g}$ atom $\mathrm{C}$ ), $\pi$ is the SR of the precursor $(\mu \mathrm{Ci} / \mathrm{g}$ atom $\mathrm{C}$ ) and $t$ is time after injection (Knox et al. 1967). Values calculated on this basis, using results obtained in the present experiments, are given in Table 4. 
Table 5. Contribution of caecal volatile fatty acids (VFA) to maintenance energy requirements in different animal species

\begin{tabular}{|c|c|c|c|}
\hline Species & Technique used & $\begin{array}{c}\text { Contribution } \\
\text { to } \\
\text { maintenance } \\
\text { energy } \\
(\%)\end{array}$ & Source of results \\
\hline Sheep & In vitro incubation & $5-9$ & $\begin{array}{l}\text { Allo, Oh, Longhurst \& } \\
\text { Connolly (1973) }\end{array}$ \\
\hline Sheep & In vivo isotope dilution & $9 \cdot \mathbf{I}$ & Faichney (1969) \\
\hline $\begin{array}{l}\text { Deer (Odocoileus } \\
\text { hemionus columbiantus) }\end{array}$ & In vitro incubation & I'O & Allo et al. (1973) \\
\hline Rat & $\begin{array}{l}\text { Post-mortem analysis at } \\
\text { intervals after feeding }\end{array}$ & $9 \cdot 4$ & $\begin{array}{c}\text { Yang, Manoharan \& } \\
\text { Mickelsen (I970) }\end{array}$ \\
\hline $\begin{array}{l}\text { Porcupine (Eretizon } \\
\text { dorsatum epixanthum) }\end{array}$ & In vitro incubation & $16-33$ & $\begin{array}{l}\text { Johnson \& McBee } \\
\text { (1967) }\end{array}$ \\
\hline Rabbit & In vitro incubation & $10-12$ & $\begin{array}{l}\text { Hoover \& Heitmann } \\
\text { (1972) }\end{array}$ \\
\hline Rabbit & $\begin{array}{l}\text { Absorption rates calculated } \\
\text { from blood VFA levels } \\
\text { and blood flow }\end{array}$ & $27 \cdot 5$ & $\begin{array}{l}\text { R. T. McMillan } \\
\text { (unpublished results) }\end{array}$ \\
\hline Rabbit & $\begin{array}{l}\text { In vivo isotope dilution; } \\
\mathrm{I} 00 \mathrm{~g} \text { food/d or feeding } \\
\text { ad lib. }\end{array}$ & $\begin{array}{l}40 \cdot 5 \\
29 \cdot 2\end{array}$ & Present study \\
\hline
\end{tabular}

These indicated that there was considerable synthesis of butyric acid from acetic acid, with evidence of some conversion of both butyric and propionic acids to acetic acid.

\section{DISCUSSION}

The use of the single-injection technique for the measurement of the production of individual VFA can be criticized, in that representative samples can only be obtained after a period of mixing of the tracer within the metabolic pool. Extrapolation is necessary to obtain initial values for SR, and this limits the precision of both pool size and interconversion values. This may be particularly important in the assessment of the known interconversions of acetate and butyrate (Annison, 1972). The possibility of changing pool size during the course of sampling, although not measured, is less likely to have a significant effect in the present experiments due to the shorter period of sampling $(2 \mathrm{~h})$ when compared with ruminant studies (8-10 h). The greater viscosity of caecal material may also be of significance by providing less stratification of digesta than might be expected in the rumen. It was noticeable in dialysis samples taken every 15 min that the concentration of VFA varied very little over the experimental period, indicating a relatively constant concentration in the caecal material. The problems of interconversion of VFA were also apparent in this study, and it may be that a continuous-infusion technique would give a more complete picture.

Pool size estimations derived by extrapolation of the regression lines of these experiments are in agreement with values obtained previously from analysis of total 
caecal contents of rabbits given the same diet (McMillan, Edwards \& Parker, 1975). The results obtained here indicated that for the two feeding regimens the pool sizes for the individual VFA were not different, except that for butyric acid which was higher in the animals fed $a d$ lib. This difference may reflect a shift in fermentation pattern in the caecum under these conditions.

Although the results in Table 3 do not indicate production rates for each VFA, values are given for the total flux of VFA through the caecal pool, including interconversion of the acids. Analysis of variance of the results obtained for the two feeding regimens indicated significant differences in the kinetics of the VFA within the caecal pool. The turnover rates were higher for the rabbits given $100 \mathrm{~g}$ food/d, when compared with those fed ad lib. although, except for acetic acid, the total flux through the pool in $24 \mathrm{~h}$ was similar in both instances. The reason for the reduction in turnover rate for acetic acid is not obvious unless there is selective absorption of VFA under certain conditions. This would appear to be unlikely as it has been found that the VFA pass into the bloodstream by simple diffusion, with little metabolism in the caecal wall (Henning \& Hird, I972; McMillan et al. 1975). Apart from metabolism of VFA in the caecum itself, the only other loss to the pool is by removal of digesta to the colon and rectum, and it is not known how this varied between the two groups of rabbits. The values for turnover rate indicated that all three VFA had similar flux rates through the caecal pool, and these rates are considerably higher (tenfold) than those calculated for the rumen of the cow using a similar method (Knox et al. 1967).

It is possible to calculate the potential contribution of the VFA to the energy requirements of the animal from the values for total flux, taking into account the energy values for the individual VFA. This calculation gives values of 269 and $194 \mathrm{~kJ} / 24 \mathrm{~h}$ for the rabbits given $100 \mathrm{~g}$ food/d and those fed ad $l i b$. respectively, which represents 40.5 and $29.2 \%$ of the maintenance energy requirements of the animals. These values may be compared with those obtained with other species (Table 5); the results obtained in the present study are of the same order as the maximum value recorded in studies with caecal digesta from porcupines (Eretizon dorsatum epixanthum) (Johnson \& $\mathrm{McBee}, 1967$ ), but are considerably higher than those obtained in an in vitro study using rabbits (Hoover \& Heitmann, 1972). In our rabbits the apparent digestibility of fibre, as determined by the modified aciddetergent-fibre method (Clancey \& Wilson, I966), was 0.25I (A. G. Stephens, unpublished results) compared with 0.34 in the rabbits used in the in vitro study of Hoover \& Heitmann (1972). Fibre digestion is thought to occur in the caecum and colon of the non-ruminant herbivore, although it is not the only substrate available for fermentation, and it is probable that the presence or absence of other materials has a greater influence on fermentation rate. It has been found, for example, that feeding high-energy commercial diets to rabbits results in a proportion of the soluble-carbohydrate fraction being available for fermentation in the caecum (A. G. Stephens, unpublished results), although results from in vitro studies (Hoover \& Heitmann, 1972) indicated no significant difference in fermentation rates in caecal material from animals given diets containing 147 and $294 \mathrm{~g}$ acid-detergent fibre $/ \mathrm{kg}$. 
The kinetic characteristics of the VFA in the caecum of the rabbit, as indicated by the present work, suggested that there were rapid rates of fermentation and high flux rates through the caecal pool. There was, however, no indication that changes in the flux rates might have occurred over a longer sampling period; it is hoped to study this, using a continuous-infusion method, to analyse more fully the interconversion of VFA found in these experiments (Table 4). Although the synthesis of butyric acid from acetic acid was found to be extensive, there was little evidence for the synthesis of propionic acid from this precursor, as reported in the caecum (Faichney, 1969) and rumen (Bergman, Reid, Murray, Brockway \& Whitelaw, 1965) of the sheep. The biochemical pathways of fermentation by the microbial population of the caecum are not as well understood as those of the rumen and it would seem that there are differences between the two sites. This may reflect the variation in substrate availability at different sites in the alimentary tract as well as changes in the microbial population. The large intestine of the rabbit has been reported to contain cocci capable of fermenting cellulose (Hall, 1952), although the range of bacterial species present is considerably smaller than that found in other animals (Williams Smith, 1965). It is not yet known to what extent this fermentation system can be altered by manipulation of the diet to further benefit the utilization of food by the animal.

The author thanks Dr A. G. Stephens for making results of his feeding trials available, and $\mathrm{Mr}$ A. J. Mould for his technical assistance. The work is supported by a grant from the Science Research Council.

\section{REFERENCES}

Allo, A. A., Oh, J. H., Longhurst, W. M. \& Connolly, G. E. (1973). J. Wildl. Mgmt 37, 202.

Annison, E. F. (1972). In Isotope Studies on the Physiology of Domestic Animals, p. 261 [A. Guillon, editor]. Vienna: International Atomic Energy Agency.

Bergman, E. N., Reid, R. S., Murray, M. G., Brockway, J. M. \& Whitelaw, F. G. (1965). Biochem. $\mathcal{F}$. 97, 53 .

Clancey, M. J. \& Wilson, R. K. (rg66). Proc. Ioth int. Grassld Congr. p. 445.

Elsden, S. R., Hitchcock, M. W. S., Marshall, R. A. \& Phillipson, A. T. (1946). F. exp. Biol. 22, I9I.

Faichney, G. J. (1969). Aust. F. agric. Res. 20, 49 I.

Gray, F. V., Jones, G. B. \& Pilgrim, A. F. (I960). Aust. Y. agric. Res. 11, $3^{83}$.

Hall, E. R. (1952). F. gen. Microbiol. 7, 350.

Henning, S. J. \& Hird, F. J. R. (1972). Biochem. F. 130, 785.

Hoover, W. H. \& Heitmann, R. N. (1972). $\mathscr{f}$. Nutr. 102, 375.

Johnson, J. L. \& McBee, R. H. (1967). Y. Nutr. 9r, 540.

Knox, K. L., Black, A. L. \& Kleiber, M. (1967). F. Dairy Sci. 5o, 1716.

Leng, R. A. (1970). In Physiology of Digestion and Metabolism in the Ruminant, p. 406 [A. T. Phillipson, editor]. Newcastle upon Tyne: Oriel Press.

McMillan, R. T., Edwards, N. A. \& Parker, D. S. (1975). Proc. Nutr. Soc. 34, 2 A.

Parker, D. S. \& McMillan, R. T. (1976). Br. F. Nutr. 35, 365.

Pickard, D. W. \& Stevens, C. E. (1972). Am. F. Physiol. 222, 116 r.

Williams Smith, H. (1965). 7. Path. Bact. 89, 95.

Yang, M. G., Manoharan, K. \& Mickelsen, O. (1970). F. Nutr. 100, 545. 